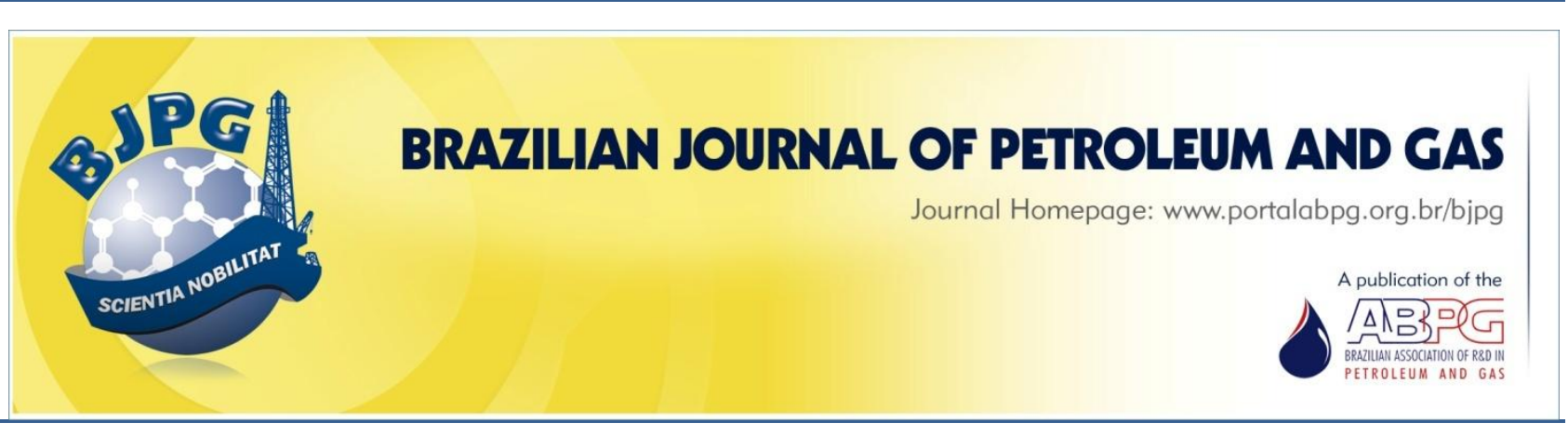

\title{
OPERATIONAL ASSESSMENTS TO IMPROVE THE MONITORING OF PETROLEUM CATALYTIC HYDRODESULFURIZATION PROCESSING
}

\author{
${ }^{\text {a }}$ Abreu, M. S. A. ${ }^{1}$; ${ }^{\text {a }}$ Abreu, C. A. M. \\ ${ }^{a}$ Federal University of Pernambuco, Department of Chemical Engineering, Recife - PE, Brazil \\ Received: 18.08.2019 / Revised: 25.10.2019 / Accepted: 31.03.2020 / Published on line: 06.05.2020
}

\begin{abstract}
The present research evaluates the operational status of hydrodesulphurization oil processing based on the monitoring of the feed oil filtration system. The system is identified as a prognostic module, designed to predict the remaining catalyst activity in the trickle bed reactor. The influence of the oil feeding flow rate of the process was evaluated with focus on the level of activity of the catalyst bed of the reactor affected by content of soluble and fine contaminants of fed oil. During an operation campaign ( 45 days) of the HDS unity (filter, reactor) variations of LHSV $\left(0.5-1.5 \mathrm{~h}^{-1}\right)$ and pressure differential in the filter (110 $200 \mathrm{Mpa}$ ) reflected in the reactor, where the activity of the catalyst diminished from $60 \%$ to $54.0 \%$. The predictions, extrapolated to 700 campaign days, indicated a catalyst deactivation of about $50 \%$, allowing a conversion of sulfur compounds around $43 \%$ to be maintained.
\end{abstract}

\section{KEYWORDS}

hydrodesulphurization; monitoring; prognostic; catalyst activity; trickle-bed reactor

\footnotetext{
${ }^{1}$ To whom all correspondence should be addressed.

Address: Federal University of Pernambuco, Department of Chemical Engineering, Recife - PE, Brazil.

ZIP Code: 50741-121 | e-mail: monicasaraujo@gmail.com

doi:10.5419/bjpg2020-0001
} 


\section{INTRODUCTION}

The dynamics of industrial processes are reflected by the evolution of the values of operational variables measured in real time through monitoring devices. The information obtained can be used for decision making in management and control of the process, and the maintenance of the assets involved. The evaluation of the behavior of the process by methods of SHM (Structure Health Monitoring) is based on monitoring data to inferences about the degradation of systems (equipment) through treatment, analysis, and modeling of data. Thus, diagnosis, prognosis and forecasts of the remaining useful life of the asset are elaborated.

An analysis of the operational data allows the elaboration of a model characterized by establishing a correlation between damage indicators observed in the equipment and sensor. The model examines the behavior of the degradation of these indicators and their influence on the operational degradation of the main system.

In the petroleum industry, the application of SHM is widespread in the context of conditionbased maintenance (CBM), involving decisions and maintenance strategies in the diagnosis and prognosis of equipment health. In on-shore and offshore operations, and at refineries, SHM is applied to equipment subject to condition monitoring (Telford et al., 2011).

Process monitoring data were used as input and output to train models through learning tools (Sadighi et al., 2013; Vasseghian \& Ahmadi, 2014). The evaluation of the operation of the HDS process, during the campaign time focused on the reactor and its feed oil pretreatment system, considers the temporal functionality of the two subsystems (filter, reactor) and its operational dependence.

The present work applies a methodology to estimate the operational state of the trickle-bed reactor for hydrodesulfurization (HDS) of petroleum based on the conditions of the feed oil filtration system. We established a prognostic module to predict trickle bed reactor performance and to evaluate the influence of the main operating condition LHSV (oil feeding flow rate) of the HDS process. The analysis focused on the level of activity of the catalyst bed of the reactor affected by the oil content in soluble and fine contaminants.

\section{METHODOLOGY}

In order to evaluate the dynamics of the hydrodesulfurization, we monitored a filtration operation upstream of the trickle-bed reactor, providing information that was correlated with the evolution of the deactivation of the catalyst in the reactor bed (Figure 1).

The monitoring was conducted in terms of the independent variable oil feed rate $(Q)$ and the pressure differential in the filter $\left(\Delta \mathrm{P}_{\mathrm{f}}\right)$, for which an

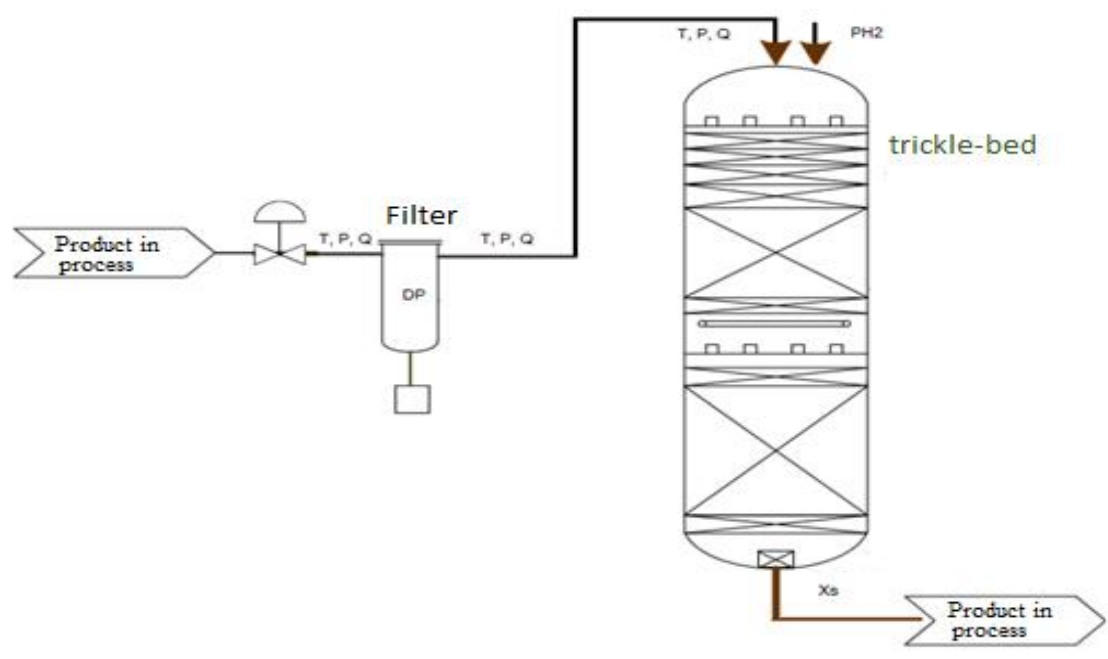

Figure 1. Unit of HDS processing. Trickle bed reactor and feed oil pre-treatment system. 
Table 1. Characteristics of process unities and operating variables (Jarullah et al., 2011).

\begin{tabular}{ll}
\hline Variables & Values \\
\hline LHSV & 0.5 a $1.5\left[\mathrm{~h}^{-1]}\right.$ \\
Temperature & 335 a $400\left[{ }^{\circ} \mathrm{C}\right]$ \\
Pressure & 4 a $10[\mathrm{MPa}]$ \\
$\mathrm{H}_{2}$ /oil ratio & $250.0 \times 10^{-3}\left[\mathrm{~m}^{3} / \mathrm{m}^{3}\right]$ \\
\hline
\end{tabular}

operational relationship with the catalyst activity was established. The pressure differential was assumed as the indicator of damage in the filter operation, while the activity of the catalyst was established as the performance indicator for the operation of the reactor. The flow of the oil in the filter was kept within a flow rate range, considering acceptable limits of variation of the pressure differential, to guarantee an output flow to the reactor feed. The proposed method was applied to the HDS process (Jarullah et al., 2011), operated in trickle bed reactor, processing crude oil (33.84 API, density 0.8558 at $15.6{ }^{\circ} \mathrm{C}$, viscosity $5.7 \mathrm{cSt}$ at 37.8 $\left.{ }^{\circ} \mathrm{C}\right)$. The $65.0 \times 10^{-2} \mathrm{~m}$ height reactor $\left(20.0 \times 10^{-3} \mathrm{~m}\right.$ diameter) operated with $60.3 \times 10^{-3} \mathrm{~kg}$ of catalyst (Co-Mo/gama-Al ${ }_{2} \mathrm{O}_{3} ; \mathrm{dp}=1,8 \times 10^{-3} \mathrm{~m} ; \mathrm{Sp}=180 \mathrm{~m}^{2} / \mathrm{g}$, $\mathrm{Vp}=0.50 \times 10^{-6} \mathrm{~m}^{3} / \mathrm{g}$, density $\left.=0.67 \times 10^{6} \mathrm{~g} / \mathrm{m}^{3}\right)$, and included two sections of inert solids. Table 1 lists the values of operating variables.

The pressure differential of the filter $\left(-\Delta P_{F}\right)$ was according to the oil flow. Its values were compared with those estimated by the Ergun equation (Ergun, 1952):

$$
\begin{aligned}
& \frac{\left(-\Delta P_{F}\right)}{L}=150 \frac{\left(1-\varepsilon_{m}\right)^{2} \mu}{\left(\varepsilon_{m}\right)^{3}\left(d_{p}\right)^{2}} U_{0}+ \\
& +1.75 \frac{\left(1-\varepsilon_{m}\right) \rho_{f}}{\left(\varepsilon_{m}\right)^{3}\left(d_{p}\right)} U_{0}^{2}
\end{aligned}
$$

The activity of the catalyst, expressed as $A c=f$ $(t, T)$, was based on the data obtained by Bellos et al. (2005) for oils with different contaminant compositions. The methodology employed considered the following:

- characterization of the operation of the HDS process in terms of the variables LHSV, temperature;

- evaluation of the filter operation in terms of LHSV and porosity;
- establishment of correlations between the pressure differential measured in the filter bed and the catalyst activity in the reactor;

- use of pressure differential in filter bed as a catalyst activity sensor;

- prediction of the operational life of the HDS reactor.

\section{RESULTS AND DISCUSSION}

In the operation of the HDS process according to reaction unit (Figure 1), the oil feed stream toward the reactor was submitted to the filtration to retain contaminants (soluble chemicals, particulates). During the operation, the filter was cleaned or changed due to the increasing incrustations in its bed. Thus, to guarantee a feeding flow to the reactor, we predicted that the oil flow in the filter should be kept within a flow rate range, taking into consideration the acceptable limits of variation of its pressure differential. Figure 2 (a, b, c) represents the dynamic behavior of oil filtration employed in the HDS operation. Thus, the following oil flow rate variations (Figure 2a) were predicted for the filter, where repercussions on the filter porosity (Figure $2 \mathrm{~b}$ ) and pressure differential (Figure 2c) were established.

The operation began with LHSV $1.5 \mathrm{~h}^{-1}$ (Fig. 2a). Then, we observed a slight decrease in the porosity in the filter bed (Fig. 2b) and a corresponding increase in pressure differential (Fig. 2c). After a certain time, the maximum pressure accepted $\left(\Delta \mathrm{P}_{\mathrm{F}} \max =2.3 \Delta \mathrm{P}_{\mathrm{F}} \mathrm{min}\right)$ was reached when the first cycle was completed. Then, a smaller LHSV was operated, so that the $\Delta \mathrm{P}_{\mathrm{F}}$ would return to the lower limit, and a new cycle started. In the whole operation, the LHSV decreased until $0.5 \mathrm{~h}^{-1}$, reaching 0.7 porosity. At the end of operation, the filter was replaced.

The predicted behavior indicated in Figure 2 was obtained in HDS operations, where the variations were measured in terms of LHSV and pressure differential in the filter. These variations reflected in the reactor show the activity of the catalyst, and were indicated as Sulphur compounds conversion (Figure 3). 


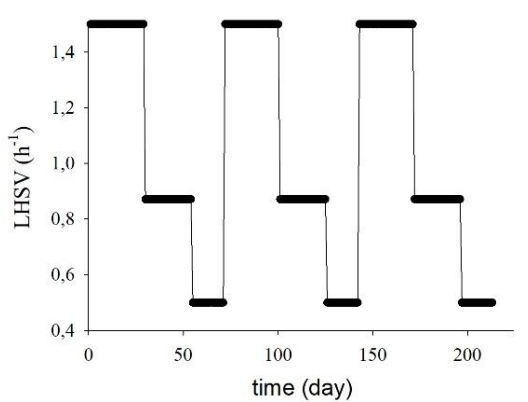

(a)

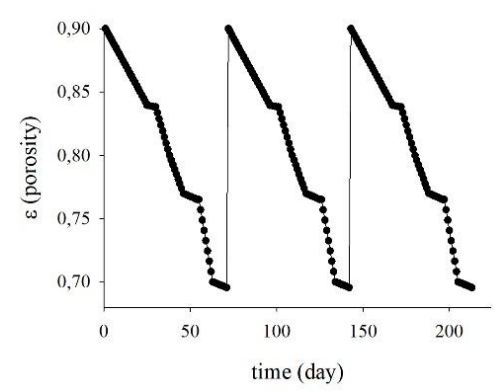

(b)

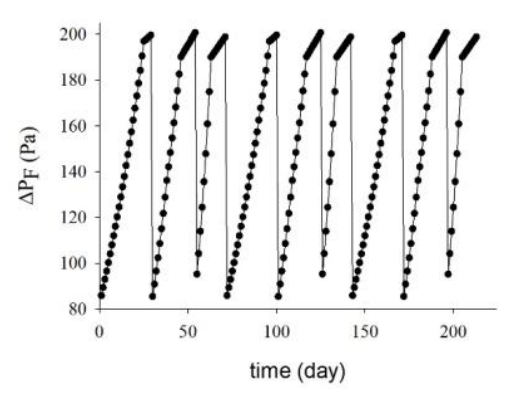

(c)

Figure 2. Operating dynamics employed for the oil filtration in feeding of the HDS reactor. (a) oil LHSV vs. time, (b) porosity vs. time, (c) pressure differential vs. time.

Under these conditions, it was observed that the filter porosity changed during the operation, characterizing its temporal dependence. This dependent relationship indicated two outcomes, considering that oil flow rate that feeds the reactor must be maintained. First, there was the direct effect, increasing the pressure differential in the filter (110 - $200 \mathrm{MPa})$. Then, there was an affect in reactor performance, decreasing catalyst activity. In this case, the oil flow rate was maintained, but its composition changed increasing the contaminant content in the oil feeding towards the reactor.

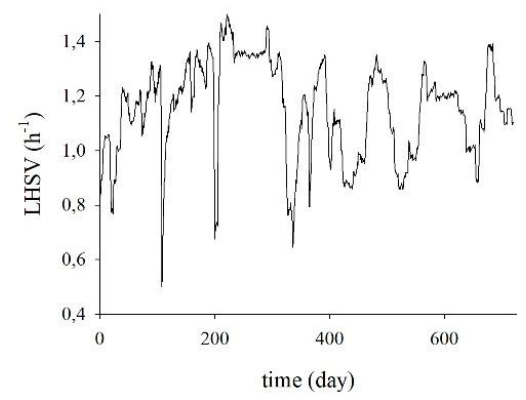

(a)

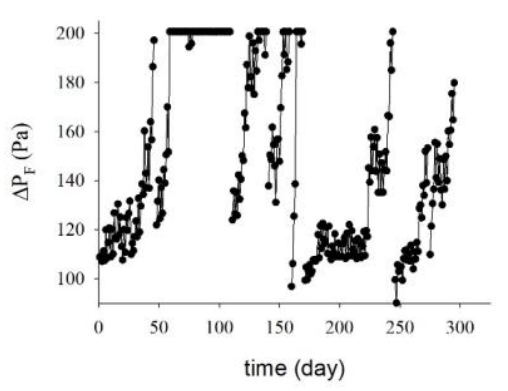

(b)

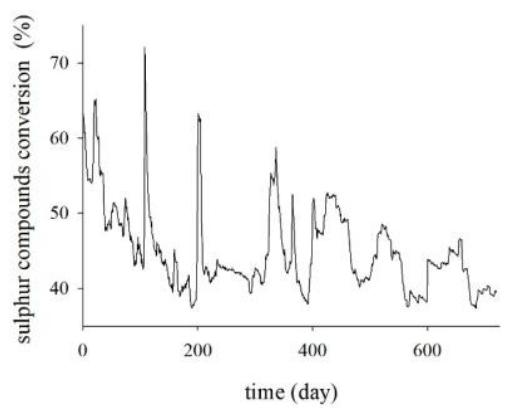

(c)

Figure 3. Evolutions of LHSV and pressure differential in the filter system, and Sulfur compound conversions in the trickle-bed reactor. (a) oil LHSV vs. time, (b) pressure differential vs. time, (c) Sulphur compounds conversion vs. time.

To equate the dynamics of the filter effects (sensor) versus the reactor performance, the correlations observed were adjusted in terms of the Ergun correlation variables $\left(\Delta \mathrm{P}_{\mathrm{F}}, \varepsilon\right)$ evolving the pressure differential in the filter and the catalytic activity $\left(A c=A c_{0}-\gamma t\right.$; Bellos et al., 2005) in the reactor. Increases in pressure differential were caused by the retention of contaminants and could lead to its saturation. In this case, the fluid started to percolate the filter with increased concentration of contaminants in the reactor feed, promoting the deactivation of the catalytic bed. 
The correlations between catalyst activity (reactor) and pressure differential (filter) were applied for an operation cycle. Figure 4 shows the predictions indicated by these correlations.

Following the methodology developed, an operation campaign (45 days) of the HDS unity (filter, reactor) was evaluated considering the time evolution of the pressure differential measured in the filter and the activity of the catalyst in the reactor (Figure 5). To evaluate these effects, the damage behavior of the filtration system was evaluated in conjunction with the catalyst deactivation function, representing the reactor's failure behavior. Thus, in the dynamic mode, the damage sensor $\Delta P_{F}(t)$ indicated the activity level $(\mathrm{a}(\mathrm{t}))$ of the catalyst that provided the actual performance of the reactor $X(t)$.

The correlations established by Bellos et al. (2005) for the catalyst activity (Ac), observes the effects of the contaminants present in the reactor feed $\left(A c=A c_{0}-\gamma t\right)$, where $\nu$ assumed the values for the reactor feed by oils of different compositions. Thus, we used $\gamma=6.22 \times 10^{-4}$ for a heavier oil with a higher percentage of contaminants; $\gamma=64.99 \times 10^{-4}$ for an intermediate oil; and $\gamma=61.12 \times 10^{-4}$ for a lighter oil with less contaminants.

Pressure differential values were observed in two moments in time. First, during the first thirty days of operation, classified as low ( $110 \mathrm{MPa}$ ) and moderate (110 -130 MPa). Second, those measured in the last fifteen days of operation, classified as high, in the range of $140-200 \mathrm{Mpa}$. The indications in these pressure domains had repercussions in terms of decreased catalyst activity, considering the three levels of contaminant concentration in the reactor feed. Thus, according to an operation that runs on oil feed containing high contaminant content, a catalyst deactivation of about $8.50 \%$ was achieved in the $45^{\text {th }}$ day of reactor campaign. However, following indications predicted by the sensor filter through the value of the variable pressure differential, and consequent control of the oil supply with different levels of contaminants, it was possible in this same campaign to reduce catalyst deactivation to $4.25 \%$.

Considering the behavior indicated by the filtersensor $\left(\Delta \mathrm{P}_{\mathrm{F}}\right.$, Figure $\left.4 \mathrm{a}\right)$ and observed for the catalyst bed (Ac, Figure $4 \mathrm{~b}$ ), a prediction based on monitored operation procedure was calculated and

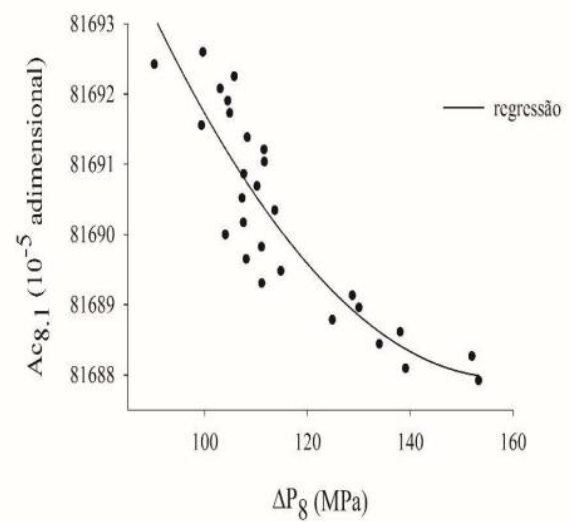

(a)

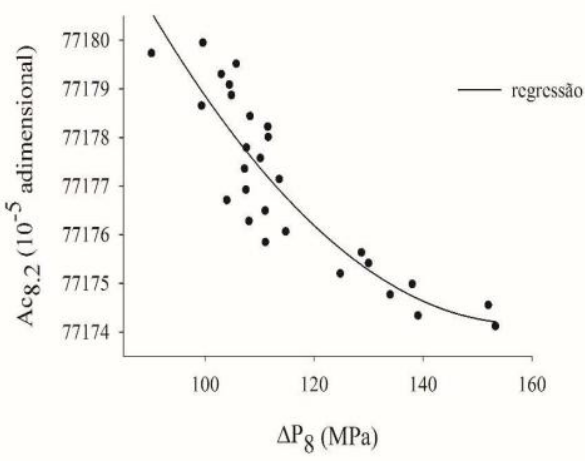

(b)

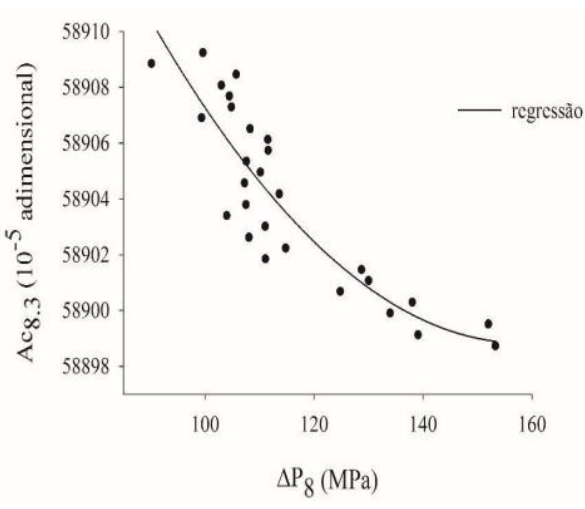

(c)

Figure 4. Catalyst activity in the reactor versus pressure differential in feed oil filter. Conditions: Operation cycle, LHSV $0.5-1.5 \mathrm{~h}^{-1}$, filter porosity $0.90-0.68$.

expressed in terms of the HDS reactor performance. In the expression, the conversion of Sulphur compounds $\left(X_{s}\right)$ was obtained $\left(X_{s}=X_{s 0} A c\right.$, where $X_{s 0}$ is the conversion for the initial activity of the catalyst). Thus, during 700 days of operation, the HDS catalyst bed was about $50 \%$ deactivated, achieving a conversion of Sulphur compounds around $43 \%$. 


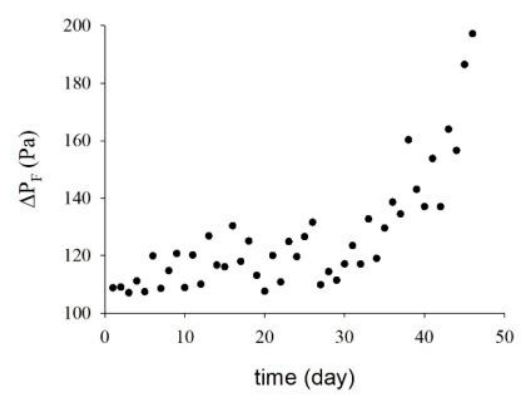

(a)

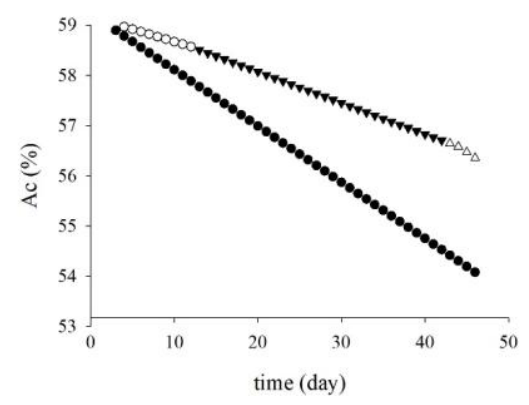

(b)

Figure 5. Operation campaign ( 45 days) of the HDS unity. a) temporal variation of pressure differential in the sensor filter, (b) decay of catalyst activity in the reactor. Monitored operation: heavy oil, $\nabla$ intermediate oil, and $\Delta$ light oil. Unmonitored operation: $\bullet$ heavy oil.

\section{CONCLUSIONS}

To predict performance and operational maintenance needs for a hydrodesulfurization fluidized bed (HDS) reactor, a fixed bed filter aligned with the oil supply was used as a sensor, characterized by its cyclic and repairable behavior.

The functionality of the sensor-reactor system involved a temporal correlation between the filtration bed porosity and the catalyst activity function in the reactor. The hydrodesulfurization evaluation operation took place in a filter porosity domain from 1 to 0.2 , with catalyst activity decrease in the range of $10-20 \%$ in 65 days.

The loss of efficiency of the HDS reactor was inferred by decreasing the conversion of petroleum sulfur compounds as a consequence of catalyst activity decay.

This research used a sensor filter methodology involving filter pressure differential and porosity, and the reactor involving the catalytic bed activity. We developed a prediction for the operational evolution of the HDS process in campaign under conditions $10 \mathrm{Mpa}, 400{ }^{\circ} \mathrm{C}, 0.87 \mathrm{~h}^{-1}$. The results achieved at the 700-day mark indicate a catalyst deactivation of about 50\%, allowing the maintenance of a conversion of sulfur compounds around $43 \%$, which is above the minimum limit of $32 \%$ allowed for HDS operation carried out by Jarullah et al. (2011).

\section{REFERENCES}

Bellos, G. D.; Kallinikos, L. E.; Gounaris, C. E.; Papayannakos, N. G. Modelling of the performance of industrial HDS reactors using a hybrid neural network approach. Chemical Engineering and Processing: Process Intensification, v. 44, p. 505515, 2005.

https://doi.org/10.1016/i.cep.2004.06.008

Ergun, S. Fluid flow through packed columns. Chemical Engineering Progress, v. 48, p. 89-94, 1952.

Jarullah, A. T.; Mujtaba, I. M.; Wood, A. S. Kinetic model development and simulation of simultaneous hydrodenitrogenation and hydrodemetallization of crude oil in trickle bed reactor. Fuel, v. 90, p. 2165-2181, 2011. https://doi.org/10.1016/i.fuel.2011.01.025

Sadighi, S.; Mohaddecy, R. S.; Norouzian, A. Optimizing an industrial scale naphtha catalytic reforming plant using a hybrid artificial neural network and genetic algorithm technique. Bulletin of Chemical Reaction Engineering \& Catalysis, v. 10, p. 210-220, 2015.

https://doi.org/10.9767/bcrec.10.2.7171.210-220

Telford, S.; Mazhar, M. I.; Howard, I. Condition Based Maintenance (CBM) in the oil and gas industry: An overview of methods and techniques. In: International Conference on Industrial Engineering and Operations Management, 2011, Kuala Lumpur, Malaysia, Proceedings IEOM Research Solutions, 2011. p. $22-24$.

Vasseghian, Y.; Ahmadi, M. Artificial Intelligent modeling and optimizing of an industrial hydrocracker plant. Journal of Chemical and Petroleum Engineering, v. 48(2), p. 125-137, 2014. 